\title{
METODA PENGENDALIAN KUALITAS UNTUK UMKM
}

\author{
Merita Bernik, dan Wa Ode Zusnita \\ Fakultas Ekonomi dan Bisnis, Universitas Padjadjaran \\ E-mail: merita.bernik@unpad.ac.id
}

\begin{abstract}
ABSTRAK. Kota Cirebon terkenal dengan sentra batiknya, akan tetapi masih banyak produk-produk lainnya yang dihasilkan dari UMKM. Hal tersebut terbuki dengan apa yang terjadi di kecamatan Talun Kabupaten Cirebon. Disana banyak sekali rumah tangga yang memiliki usaha sebagai pengrajin alat-alat kebersihan rumah tangga, pembuat kue kering dan basah, produksi pakaian dan masih banyak lagi. Dengan semakin majunya UMKM dan berdampak pada persaingan yang semakin ketat, maka diharapkan UMKM yang berada di kecamatan Talun ini dapat berkembang dan meningkatkan kualitas produknya. Salah satu kendala yang dihadapi oleh UMKM di kecamatan Talun adalah tidak memiliki pemahaman bagaimana cara mengendalian produksi agar dapat menghasilkan produk yang berkualitas dan mampu bersaing di pasaran. Berdasarkan hal tersebut maka diperlukan suatu metoda pengendalian kualitas yang mudah untuk dipahami dan juga diterapkan oleh UMKM di kecamatan Talun Kabupaten Cirebon. Dalam kegiatan ini metode pelaksanaan yang dipergunakan adalah metode Deplat Partisipatif yaitu melakukan kegiatan dalam bentuk pemberian penyuluhan dan bimbingan mengenai implementasi pengendalian kualitas pada pengrajin di Kecamatan Talun Kabupaten Cirebon. Berdasarkan hasil wawancara diperoleh bahwa metoda pengendalian kualitas yang mudah untuk diterapkan adalah dengan menggunakan SOP, sedangkan hasil dari wawancara dan kuesioner yang disebrakan kepada UMKM di kecamatan Talun kabupaten Cirebon, mereka lebih memahami mengenai kualitas, perntinya terdapat standar kualitas, dan mengetahui meroda pengendalian kualitas yang mudah untuk diterapkan.
\end{abstract}

Kata kunci: UMKM; Kualitas; Standar Kualitas; Pengendalian Kualitas

\section{QUALITY CONTROL METHODS FOR MSMES}

\begin{abstract}
Cirebon city famous for its batik center, but still many other products produced from SMEs.It is exposed to what happened in Talun sub-district of Cirebon. There are many households who have business as household handicraft makers, cake maker, clothing production and many more. With the progress of SMEs and impact on the increasingly fierce competition, it is expected that SMEs in Talun can grow and improve the quality of its products. One of the obstacles faced by SMEs in Talun district is not having an understanding how to control production in order to produce quality products and able to compete in the market. Based on the above, it needs a quality control method which is easy to be understood and also implementation by SMEs in Talun Cirebon. In this activity the implementation method used is the method of Participatory Deplat is doing activities in the form of counseling and guidance on quality control methods on craftsmen in Talun Cirebon. This counseling and mentoring activities are conducted in the form of providing structured training. Based on interview result, it is found that the method of quality control that is easy to be applied is by using SOP, while the result of interview and questionnaires distributed to SMEs in Talun Cirebon, they are more understanding about quality, quality standard, and know the method of quality control that easy to be implementation.
\end{abstract}

Key words: SMEs; Quality; Quality Standard; Quality Control

\section{PENDAHULUAN}

Kota Cirebon merupakan salah satu kota yang menjadi destinasi wisata di pulau Jawa. Selain terkenal dengan makanan khas Cirebon, juga terkenal batik yang menjadi ciri khas kota Cirebon terutama motif megamendung. Dengan semakin majunya kota Cirebon, maka semakin banyak juga UMKM penghasil batik. Apabila kita berkunjung ke kota Cirebon dan berniat untuk membeli batiknya, maka akan teringat kepada kawasan batik Trusmi. Kawasan Trusmi ini merupakan penghasil batik baik dalam bentuk UMKM yang menjual hasil batiknya di rumah hingga yang memiliki toko sendiri.

UMKN yang berada di kota Cirebon memiliki produk yang sebenarnya dari segi kualitas sudah cukup baik, akan tetepi para pelaku bisnis ini tidak dapat menghasilkan produk dengan standar kualitas yang sama. Permasalahan utama yang mereka miliki adalah mengenai pengendalian kuaitas yang mereka lakukan. Para pelaku bisnis ini melakukan pendalian kualitas hanya berdasarkan pengalaman sebelumnya, proses kerja yang tidak berurutan, pengulangan kesalahan yang sama, tidak adanya pedoman kerja yang terdokumentasi. Hal tersebut terjadi selain pada UMKM batik juga terjadi pada UMKM di kecamatan Talun Kabupaten Cirebon. Disana banyak sekali rumah tangga yang memiliki usaha sebagai pengrajin alat-alat kebersihan rumah tangga, pembuat kue kering dan basah, produksi pakaian dan masih banyak lagi. Produk yang dihasilkan tidak memiliki kualitas yang sama, seperti tingkat kematangan dari kue kering dan basah yang berbeda-beda, sapu lidi yang ketebalannya berbeda-beda, sapu injuk juga mengalami hal yang sama jumlah serabutnya tidak standar.

Dengan semakin majunya UMKM dan berdampak pada persaingan yang semakin ketat, maka diharapkan UMKM yang berada di kecamatan Talun ini dapat berkembang dan meningkatkan kualitas produknya. Berdasarkan hal tersebut, maka perlu diketahui proses pengendalian kualitas yang selama ini dilaksanakan oleh pera pengrajin yang ada di Kecamatan Talun Kabupaten Cirebon dan metoda pengendalian kualitas apa saja yang cocok untuk diterapkan oleh para pengrajin di Kecamatan talun Kabupaten Cirebon 


\section{Pengendalian Kualitas}

Pengandalian kualitas dalam Barterfield (2012) adalah penggunaan tehnik dan aktivitas untuk mencapai, mempertahankan, dan meningkatkan kualitas barang atau jasa. Hal ini mencakup tehnik dan kegiatan berikut ini :

a. Spesifikasi kebutuhan

b. Desain produk atau jasa yang dapat memenuhi spesifikasi

c. Produksi atau instalasi untuk memenuhi kebutuhan spesifikasi sepenuhnya

d. Inspeksi atau memastikan kesesuaian produk dengan spesifikasi

e. Meninjau penggunaan untuk meyediakan informasi untuk keperluan revisi spesifikasi

\section{Process Flow Diagram}

Process flow diagram adalah diagram skematis yang menggambarkan aliran perpindahan produk atau jasamelalui stasiun-stasiun proses atau operasi. Diagram ini memudahkan visualisasi dari keseluruhan sistem, mengidentifikasi titik masalah yang potensial, dan mencari kegiatan pengendalian.Process flow diagram adalah diagram skematis yang menggambarkan aliran perpindahan produk atau jasamelalui stasiun-stasiun proses atau operasi (Goetsch, 2010).

Diagram alir yang terbaik adalah yang dibuat oleh tim, karena jarang sekali satu individu memahami seluruh proses.Perbaikan proses dapat dilakukan dengan menghilangkan langkah-langkah, menggabungkan langkahlangkah atau membuat langkah-langkah yang sering digunakan menjadi lebih efisien (Taguge, 2005).

\section{METODE}

Dalam kegiatan ini metode pelaksanaan yang dipergunakan adalah metode Deplat Partisipatif yaitu melakukan kegiatan dalam bentuk pemberian penyuluhan dan bimbingan mengenai implementasi pengendalian kualitas pada pengrajin di Kecamatan Talun Kabupaten Cirebon.

Kegiatan penyuluhan dan bimbingan ini dilaksanakan dalam bentuk memberikan pelatihan tersruktur. Tahapan Kegiatan Pengabdian Kepada Masyarakat yang akan dilaksanakan adalah sebagai berikut:

\section{Tabel 1 Tahapan Kegiatan}

\begin{tabular}{|c|c|}
\hline No & Tahapan Kegiatan \\
\hline 1 & $\begin{array}{l}\text { Mengidentifikasi pengrajin di Kecamatan Talun } \\
\text { Kabupaten Cirebon }\end{array}$ \\
\hline 2 & $\begin{array}{l}\text { Membuat draf wawancara mengenai metoda pengendalian } \\
\text { kualitas yang dilakukan selama ini }\end{array}$ \\
\hline 3 & $\begin{array}{l}\text { Menentukan metoda pengendalian kualitas yang mudah } \\
\text { untuk dipahami dan diimplementasikan }\end{array}$ \\
\hline 4 & Menentukan jadwal pelatihan \\
\hline 5 & Membuat bahan pelatihan yang efektif dan efisien \\
\hline 6 & Melaksanakan pelatihan \\
\hline 7 & Membuat kuesioner untuk evaluasi hasil pelatihan \\
\hline 8 & $\begin{array}{l}\text { Mengidentifikasi pengrajin yang memiliki potensi untuk } \\
\text { dapat mengiplementasikan metoda pengendalian kualitas }\end{array}$ \\
\hline
\end{tabular}

Dalam menentukan UMKM yang akan diberikan pelatihan dengan menggunakan metoda kualitatif, dimana dilakukan pengambilan sampel berdasarkan teknik nonprobability sampling karena tidak semua UMKM di kota Cirebon akan dijadikan sampel. Teknik yang dipergunakan adalah purposive sampling, dengan mengambil sampel sebanyak 24 UMKM di kecamatan talun Kabupeten Cirebon. Wawancara dan penyebaran kuesioner dilakukan untuk mendapatkan data yang diperlukan untuk dapat mementukan metoda pengendalian kualitas yang tepat untuk dapat diterapkan oleh UMKM tersebut.

\section{HASIL DAN PEMBAHASAN}

\section{Pengendalian Kualitas untuk UMKM di Kecamatan Talun Kabupaten Cirebon}

Berdasarkan hasil wawancara yang dilakukan kepada 24 pengrajin di Kecamatan Talun Kabupaten Cirebon, maka diperoleh hasil bahwa:

- Pengrajin menyadari pentingnya kualitas produk

- Belum memahami bagaimana sebaiknya mempertahankan kualitas produknya

- Sudah menjalankan pengendalian kualitas, tetapi belum mengetahui bagaimana seharusnya pengendalian itu dilakukan

- Membutuhkan alat yang mudah untuk membantu mereka melakukan pengendalian kualitas produknya

- Belum terdapatnya standar produk yang ditetapkan, masih berdasarkan pengalaman dan tidak adanya keseragaman.

Maka berdasarkan hasil di atas, pengendalian kualitas yang mudah untuk dipahami dan diterapkan adalah dengan menggunakan SOP (Standar Operation Procedure) (Sailendra, 2015). Alasan mengapa alat pengendalian kualitas ini dipilih karena

- Dengan adanya prosedur, maka cara dan langkah mereka dalam bekerja akan lebih jelas (Heizer, 2012)

- Dapat diketahui jalur kritis yang seharusnya dilakukan pengontrolan (Ishikawa, 1982)

- Keseragaman dalam melakukan suatu pekerjaan

- Mudah mengetahui kesalahan yang dilakukan

- Mudah untuk dibuat dan diimplementasikan

Pembuatan SOP (Standar Operating Procedure)

Prosedur merupakain uraian dan langkahlangkah yang harus dilaksanakan ketika kita akan melakukan suatu pekerjaan. Prosedur yang baik adalah prosedur yang dapat menjawab

$\square$ What/apa : (tugas)

$\square$ Who/siapa : wewenang, tanggung jawab

When/kapan : kapan dilakukan?

Where/dimana : menunjukkan bagian/divisi/dept.

Why/kenapa : kenapa dilakukan 
Isi dari prosedur itu sendiri terdiri dari

1. Tujuan prosedur

2. Ruang lingkup

3. Daftar istilah atau definisi

4. Referensi

5. Distribusi

6. Uraian Prosedur

7. Lampiran formulir, checklist atau label yang dipakai

Uraian dari isi prosedur adalah sabagai berikut: Pernyataan yang menunjukan tujuan dari prosedur dan pernyataan kebijakan dari prosedur ini. Dalan tujuan ini harus dijelaskan untuk apa prosedur tersebut dibuat.

Menjelaskan personil, unit organisasi, dokumen, dan proses- proses yang terpengaruh prosedur ini. Menunjukan bahwa prosedur ini berlaku atau akan dijalankan oleh unita tau bagian yang mana dalam suatu organisasi. Berisikan istilah ataupun definisi yang tidak semua orang paham ataupun mengetahuinya.

Apabila kita membuat langkah-langkah pengerjaan ataupun menentukan suatu kegiatan tertentu berdasarkan pada suatu pedoman, panduan yang berlaku di perusahaan, ataupun peraturan lokal, peraturan pemerintah dll. Merupakan bagian/unit dari suatu organisasi yang harus mengetahui dan juga memahami isi dari prosedur terssebut. Berisikan langkah-langkah yang diuraikan secara detail dan dapat menjawab $5 \mathrm{~W} 1 \mathrm{H}$

Untuk memperjelas ataupun mempertegas kegiatan dan langkah yang harus dilakukan, maka dapat dibantu dengan membuat Flow Chart. Disertakan juga lampiran berupa form, kwitansi, ataupun data, record, dokumendokumen yang terkait lainnya.

Berdasarkan hasil pelatihan pengendalian kualitas yang diberikan, maka UMKM di kecamatan Talun ini mencoba membuat prosedur pengendalian kualitas untuk setiap produk yang dihasilkannya, seperti:

- Prosedur pengendalian kualitas pembuatan kue kering

- Prosedur pengendalian kualitas pembuatan sapu injuk

- Prosedur pengendalian kualitas pembuatan sapu lidi

Dengan dibuatnya prosedur tersebut, maka setiap kegiatan produksi yang mereka lakukan berpedoman pada langkah-langkah yang terdapat dalam prosedur, mulai dari input seperti pemilihan bahan baku, proses seperti urutanurutan pekerjaan yang harus dilakukan, cara pengontrolan dari hasil pekerjaan disetiap langkahnya, dan output seperti warna yang dihasilkan, ketebalan, berat jenis dan cara pengepakan. Sehingga dengan adanya prosedur pengendalian kualitas tersebut, akan dihasilkan produk yang sama atau dapat dikatakan memiliki standar kualitas produk yang dapat dipertanggung jawabkan kepada konsumen dan tentu saja dapat bersaing dengan produk sejenis dipasaran.

\section{Evaluasi Pemahaman Kualitas dan Pelaksanaan Pelatihan}

Setelah dilaksanakannya pelatihan dan pendampingan, maka disebarkan kuesioner kepada para pengrajin di kecamatan Talun, kabupaten Cirebon, dijelaskan pada tabel 2 .

Tabel 2. Hasil Evaluasi Pemahaman Kualitas dan Pelaksanaan Pelatihan

\begin{tabular}{|c|c|c|c|c|c|}
\hline No & Pernyataan & TS & CS & $\mathrm{S}$ & SS \\
\hline 1 & $\begin{array}{l}\text { Materi yang diberikan sangat } \\
\text { bermanfaat }\end{array}$ & & 2 & 13 & 6 \\
\hline 2 & $\begin{array}{l}\text { Pelatihan menambah pengetahuan } \\
\text { dan wawasan }\end{array}$ & & & 8 & 13 \\
\hline 3 & $\begin{array}{l}\text { Pelatihan ini sebaiknya dilaksanakan } \\
\text { secara berkelanjutan }\end{array}$ & & 3 & 13 & 4 \\
\hline 4 & $\begin{array}{l}\text { Dengen adanya pelatihan ini, lebih } \\
\text { memahami mengenai kualitas }\end{array}$ & & & 10 & 11 \\
\hline 5 & $\begin{array}{l}\text { Kulitas produk sangat penting untuk } \\
\text { dipertahankan dan ditingkatkan }\end{array}$ & & & 8 & 13 \\
\hline 6 & $\begin{array}{l}\text { Saya mengetahui adanya standar } \\
\text { kualitas }\end{array}$ & & 1 & 18 & 2 \\
\hline 7 & $\begin{array}{l}\text { Standar kualitas telah ditetapkan dan } \\
\text { dikomunikasikan }\end{array}$ & 1 & 3 & 13 & 4 \\
\hline 8 & $\begin{array}{l}\text { Pengendalian kualitas sangat } \\
\text { diperlukan }\end{array}$ & & 2 & 9 & 9 \\
\hline 9 & $\begin{array}{l}\text { Saya memahami cara pengendalian } \\
\text { kualitas }\end{array}$ & & 5 & 12 & 2 \\
\hline 10 & $\begin{array}{l}\text { Selama ini saya telah melaksanakan } \\
\text { pengendalian kualitas }\end{array}$ & & 2 & 17 & \\
\hline 11 & $\begin{array}{l}\text { Saya bersedia dan mampu untuk } \\
\text { menerapkan pengendalian kualitas }\end{array}$ & & & 15 & 5 \\
\hline 12 & $\begin{array}{l}\text { Cara pengendalaian kualitas yang } \\
\text { diberikan dalam pelatihan ini cukup } \\
\text { mudah }\end{array}$ & & 6 & 14 & 1 \\
\hline 13 & $\begin{array}{l}\text { Saya ingin mengetahui jenis } \\
\text { pengendalian kualitas yang lainnya }\end{array}$ & & 7 & 11 & 8 \\
\hline
\end{tabular}

Berdasarkan hasil penyebaran kuesioner di atas, sebanyak $76,92 \%$ peserta pelatihan menyatakan setuju dan $23,08 \%$ menyatakan sangat setuju atas pernyataan yang diberikan berkenaan dengan pentingnya pemahaman mengenai kualitas, cara pengendalian kualitas yang diberikan dalam pelatihan, dan pelatihan yang diberikan sangat bermanfaat serta menyatakan bahwa mereka membutuhkan pelatihan mengenai cara pengendalian kualitas yang lainnya.

\section{SIMPULAN}

Berdasarkan hasil yang diperoleh maka dapat disimpulkan bahwa: Pengendalian kualitas dari UMKM di kota Cirebon masih harus dilakukan peningkatan dan juga pengahaman bagaimana cara pengendalian kualitas yang efektif dan efisien. Dengan diterapkannya pengendalian kualitas yang baik dan benar, maka akan mengurangi jumlah produkyang cacat, dan juga akan mengurangi jumlah biaya yang harus dikeluarkan kerena kecacatan produk yang dihasilkan; Salah satu untuk dapat menerapkan pengendalian kualitas adalah dengan membiasakan adanyanya langkah kerja 
yang terdokumentasi, dimana langkah kerja tersebut dapat tertuang dalam prosedur pengendalian kualitas, bagaimana pengendalian atau pengontrolan yang baik dari setiap langkah kerja yang dilakukan, pengendalian dari bahan baku yang dipergunakan, pengendalian dari hasil yang diperoleh agar tidak mengalami kecacatan; Hasil evaluasi yang diperoleh dari pemahaman kualitas dan pelatihan yang diberikan menyatakan bahwa para UMKM ini $76,92 \%$ setuju dan 23,08 \% sangat setuju bahwa mereka memang harus memahami kualitas dan mengetahui cara pengenalian kualitas yang mudah untuk diterapkan.

\section{DAFTAR PUSTAKA}

Basterfield, Dale.H, 2012, Quality Control, 9th edition, Pearson Internasional
Goetsch, David.L.,2010, Quality Management for Organizatinal Excellence, Pearson International

Heizer, J., Render, B.,2012, Operations management, Upper Saddle River: Pearson Prentice Hall.

Ishikawa, K.,1982, Guide to quality control (Second Revised English Edition). Tokyo, Japan: Asian Productivity Organization.

Sailendra, Annie. 2015. Langkah-Langkah Praktis Membuat SOP. Cetakan Pertama. Trans Idea Publishing, Yogyakarta.

Taguge, N. R.,2005, The quality toolbox. (2th ed.) Milwaukee, Wisconsin: ASQ Quality Press 